\title{
Inheritance of Shortened Fruit Maturation in the Cherry Tomato Cornell 871213-1 and Its Relation to Fruit Size and Other Components of Earliness
}

\author{
Joseph M. Kemble ${ }^{1}$ and Randolph G. Gardner ${ }^{2}$ \\ Department of Horticultural Science, North Carolina State University, Raleigh, NC 27695-7609 \\ Additional index words. breeding, genetics, heterosis, heritability, Lycopersicon esculentum
}

\begin{abstract}
The heritability of shortened fruit maturation (SFM) period in Cornell 871213-1, an inbred cherry tomato [Lycopersicon esculentum var. cerasiforme (Dunal.) A. Gray] line, was estimated from a greenhouse experiment. Cornell 871213-1 was crossed with the cherry tomato line NC 21C-1. Mean fruit maturation period (FMP) (days from anthesis to the breaker stage of fruit color) was 40.8 days for $\mathrm{NC} 21 \mathrm{C}-1$ and 32.0 days for Cornell 871213-1. Parental, $F_{1}, F_{2}$, and backcross generations all differed in mean FMP and yielded, estimates of broad- and narrow-sense SFM heritabilities of $72 \%$ and $40 \%$, respectively, on a single-plant basis. A test for midparent heterosis showed significance. Genetic control of SFM was quantitative in nature and highly dominant. A field study of an $F_{2}$ population developed from the cross Cornell 871213-1 $\times$ NC 84173, the latter a large-fruited tomato line (Lycopersicon esculentum Mill.), gave a mean FMP of 48.4 and 31.2 days for NC 84173 and Cornell 871213-1, respectively. The $F_{1}$ and $F_{2}$ generations had FMP of 33.1 and 34.7 days, respectively. The parents, $F_{1}$, and $F_{2}$ generations all differed in FMP. Parental, $F_{1}$, and $F_{2}$ generations yielded an estimate of broad-sense SFM heritability of $64 \%$ on a single-plant basis. $F_{3}$ progenies from selected $F_{2} s$ were grown in a greenhouse, and $F_{3}-F_{2}$ regression analysis gave a narrow-sense $S F M$ heritability of 39\%. Parental means differed from each other and from the $F_{1}$ and $F_{2}$ means for period from sowing to anthesis, fruit weight, and locule number. $F_{1}$ and $F_{2}$ means did not differ for any trait and were far below the midparent values, approaching Cornell 871213-1 for each trait except for the number of days from sowing to anthesis. Significant correlations existed in the $F_{2}$ generation between FMP and fruit weight $(0.61)$ and between fruit weight and locule number (0.69). Significant correlations existed between selected $F_{2} s$ and their $F_{3}$ progeny for FMP (0.53), fruit weight $(0.78)$, and days from sowing to anthesis $(0.78)$. In the $F_{3}$ generation, a significant correlation occurred between $F M P$ and fruit weight (0.48). $F_{3}-F_{2}$ regression and realized heritabilities were used as two estimates of narrow-sense heritability (29\% and $31 \%$, respectively) for days from sowing to anthesis.
\end{abstract}

Early maturity in tomato cultivars is highly desirable since early season fruit tend to bring the highest price in the fresh market (Burdick, 1954; Honma et al., 1964; Kerr, 1955). The mechanisms controlling earliness in tomato have been extensively studied (Banerjee and Kaloo, 1989; Corbeil, 1964; Currence, 1938; Lopez, 1960; Lyon, 1941; Powers, 1939; Powers and Lyon, 1941; Tayel et al., 1959). These researchers defined earliness in different ways but, in general, measured relative earliness (or lateness) as the number of days from sowing to the first ripe fruit.

In addition, researchers have examined discreet components, or stages of earliness. The time period from sowing to anthesis has been extensively studied (Banerjee and Kaloo, 1989; Corbeil, 1964; Currence, 1938; Lopez, 1960; Lyon, 1941; Powers, 1939; Powers and Lyon, 1941; Tayel et al., 1959). Powers and Lyon (1941) divided earliness into three stages: 1) days from sowing to ahthesis, 2) days from anthesis to first fruit set, and 3) days from first fruit set to first ripe fruit. They concluded that there was sufficient variation within these stages to consider each a unique and heritable trait.

Environmental factors, especially temperature and light intensity, play a significant role in the expression of any com-

\footnotetext{
Received for publication 3 Feb. 1992. Accepted for publication 18 Mar. 1992 This research was funded by the North Carolina Agricultural Research Service (NCARS), Raleigh, NC 27695-7609. This paper is based on a portion of a thesis submitted by J.M.K. in partial fulfillment of the requirements for the MS degree. We thank Martha Mutschler, Cornell Univ., for providing seed of Cornell 871213-1. The cost of publishing this paper was defrayed in part by the payment of page charges. Under postal regulations, this paper therefore must be hereby marked advertisement solely to indicate this fact.

'Graduate Research Assistant.

${ }^{2}$ Professor. Current address: Mountain Horticultural Crops Research Center, 2016 Fanning Bridge Rd. Fletcher, NC 28732-9629.
}

ponent of earliness (Kerr, 1955; Khalf-Allah and Peirce 1963, 1964; Powers and Lyon, 1941.) Earliness in tomato has been found to be a quantitatively inherited trait (Peirce and Currence, 1959) in which the heritability has ranged from moderate to high, depending on the stage measured and the cross under observation (Peirce and Currence, 1959; Tayel et al., 1959).

Dominance plays a major role in the expression of earliness and its components in inter- and intraspecific hybrids within the genus Lycopersicon. The F1 hybrid mean for earliness closely resembles that of the early parent and is often significantly earlier than the late parent (Corbeil, 1964; Daubeny, 1961; Honma et al., 1963; Lyon, 1941; Powers and Lyon, 1941; Tayel et al., 1959). Corbeil and Butler (1965), Banerjee and Kalloo (1989), and Fogel and Currence (1950) concluded that additive genetic effects also played a significant role in the expression of earliness.

Many researchers have studied the relationship between fruit size and earliness in an attempt to develop early, large-fruited cultivars (Banerjee and Kalloo, 1989; Fogel and Currence, 1950; Khalf-Allah and Peirce, 1963; Peirce and Currence, 1959; Walkof, 1955). Khalf-Allah and Peirce (1963, 1964) found that selection for earliness resulted in a decrease in fruit size. Peirce and Currence (1959) reported a positive correlation between fruit size and number of degree days to fruit ripe fruit and showed that selection for large fruit size resulted in delayed maturity. In several studies (Khalf-Allah and Peirce, 1963, 1964; MacArthur and Butler, 1983; Peirce and Currence, 1959), the environment was found to strongly influence earliness, yet was shown to have little influence on fruit size (Peirce and Currence, 1959).

Fruit weight and locule count contribute directly to overall

Abbreviations: FMP, fruit maturation period; SFM, shortened fruit maturation. 
fruit size and are, therefore, accurate measures of fruit size (MacArthur, 1941; MacArthur and Butler, 1938; Powers, 1939). Fruit weight and locule count have been shown to be highly heritable (Khalf-Allah and Peirce, 1963; Peirce and Currence, 1959; Powers, 1939). Narrow-sense heritability estimates $\left(h^{2}\right)$ for fruit weight ranged from $68.1 \%$ to $75.5 \%$, and a high correlation (0.84) was found between $\mathrm{F}_{2} \mathrm{~s}$ and their progeny for fruit weight (Peirce and Currence, 1959). In crosses between large- and small-fruited cultivars, fruit size of the $F_{1}$ hybrids typically resembles that of the smaller-fruited parent. Small fruit size is considered to be partially dominant to large fruit size (Banerjee and Kalloo, 1989; Butler, 1966; Fogel and Currence, 1950; MacArthur, 1941; MacArthur and Butler, 1938).

The cherry tomato line Cornell 871213-1 was identified in studies in North Carolina (unpublished) and in New York (M. Mutschler, personal communications) as having a shorter fruit maturation period (days from anthesis to the breaker stage of fruit maturation) than other cherry tomato lines. This component of earliness has not been studied extensively in previous research. The objectives of our studies were to 1) estimate the heritability of shortened fruit maturation period (SFM) derived from Cornell 871213-1; 2) postulate the genetic control of this trait; 3 ) determine its potential as a source of earliness for developing new cultivars and breeding lines; and 4) determine the relationship between SFM and fruit size (as determined by fruit weight and locule count) in a cross involving a large-fruited tomato.

\section{Materials and Methods}

Heritability of SFM from Cornell 871213-1 (Expt. 1). A greenhouse study conducted at the Mountain Horticultural Crops Research Station (MHCRS), Fletcher, N.C., from May-Aug. 1989 was designed to determine the heritability of SFM derived from Cornell 871213-1, an inbred cherry tomato developed at Cornell Univ. A family was developed from the cross of Cornell 871213-1 × NC 21C-1, the latter an inbred cherry tomato developed at the MHCRS. The family consisted of 24 plants each of the nonsegregating generations $-\mathrm{P}_{1}(\mathrm{NC} 21 \mathrm{C}-1), \mathrm{P}_{2}$ (Cornell 871213-1), $\quad F_{1 a}\left(P_{2} \times P_{1}\right)$, and $F_{1 b}\left(P_{1} \times P_{2}\right) ; 240$ plants of the $\mathrm{F}_{2}$ generation (selfed $\mathrm{F}_{1 \mathrm{~b}}$ ); and 120 plants each of the backcross generations $-\mathrm{BC}_{1}\left(\mathrm{~F}_{1 \mathrm{~b}} \times \mathrm{P}_{1}\right)$ and $\mathrm{BC}_{2}\left(\mathrm{~F}_{1 \mathrm{~b}} \times \mathrm{P}_{2}\right)$.

Five-week-old seedlings were transplanted into 3.75-liter pots containing a medium of 1 fine peat : 1 horticultural vermiculite : 1 pine bark (by volume) amended with appropriate nutrients. Plants received additional nutrients and water via drip emitters in the pots. Day/night cycles were maintained at 29/17C. Each plant was pruned to one stem, topped at $\approx 1.2 \mathrm{~m}$ and supported by a vertical string.

A randomized complete-block design with 12 replications was used. Each replication contained two plants each of the nonsegregating generations, $20 \mathrm{~F}_{2} \mathrm{~s}$ and 10 plants each of the backcross to each parent. Therefore, each replication contained 48 plants that were randomly assigned two plants per pot resulting in 24 pots per replication. Guard plants bordered the experimental plants.

Bright yellow flowers with petals beginning to reflex were vibrated at midday to liberate pollen. Flowers were considered to be at anthesis when pollen was shed. Five flowers per plant were tagged. Tagged flowers were checked daily to detect any that might have aborted. The fruit maturation period (FMP) was calculated as the number of days from anthesis until the initiation of fruit ripening (breaker stage), as indicated by a color change from green to pink at the blossom end of the fruit.
Narrow-sense heritability $\left(h^{2}\right)$ was calculated as the ratio of additive variation to the $\mathrm{F}_{2}$ variation: $\mathrm{s}_{\mathrm{a}}^{2} / \mathrm{s}_{\mathrm{F} 2}^{2}$. Broad-sense heritability $(\mathrm{H})$ of SFM was calculated as the ratio of genotypic variation to the $\mathrm{F}_{2}$ variation: $\mathrm{s}_{\mathrm{g}}^{2} / \mathrm{s}_{\mathrm{F} 2}^{2}$. Midparent heterosis of SFM was calculated as the difference between the $F_{1}$ and midparent means for FMP divided by the midparent mean of FMP multiplied by 100 .

Development of family: Cornell 871213-1 × NC 84173 (Expt. 2; Part 1). This experiment was conducted in the field at the MHCRS from May-Aug. 1989. A family was developed from a cross between Cornell 871213-1 and NC 84173, the latter an inbred, large-fruited tomato (L. esculentum Mill.) developed at the MHCRS. The family consisted of 12 plants each of the nonsegregating generations $-\mathrm{P}_{1}\left(\right.$ Cornell 871213-1), $\mathrm{P}_{2}(\mathrm{NC}$ 84173), and $F_{1}\left(P_{1} \times P_{2}\right)$ - and 211 plants of the $F_{2}$ generation.

Six-week-old seedlings were transplanted to the field on 21 May 1989, in two adjacent rows with a between-row spacing of $1.5 \mathrm{~m}$ and in-row spacing of $0.46 \mathrm{~m}$. Plants were staked and grown in accordance with the guidelines for growing fresh-market staked tomatoes in western North Carolina (Konsler and Gardner, 1990). Generations within the rows were planted in sets of 18 to $20 \mathrm{~F}_{2}$ s followed by one plant each of the parents and $F_{1}$ generations, replicated 12 times.

The procedure for determining anthesis and fruit maturation date was the same as that described for Expt. 1, with the exception that only four flowers per plant were tagged. Tagged fruits, harvested at the breaker stage, were weighed, and the number of locules in each fruit was recorded. In addition, a random sample of 10 ripe fruit was harvested from the middle section of each plant in midseason. Fruit fresh weight and locule count were recorded from these samples. Broad-sense heritability and midparent heterosis were calculated as in Expt. 1.

Expt. 2; Part 2. This experiment was conducted in the greenhouse at the MHCRS from Sept. 1989-Jan. 1990 using selected $\mathrm{F}_{3} \mathrm{~S}$ ( $\mathrm{F}_{3}$ seed from selected $\mathrm{F}_{2}$ plants) harvested from Expt. 2; Part 1. Selection was based on divergency for the number of days from sowing to anthesis. Ten each of the earliest and latest flowering plants were chosen.

Five-week-old seedlings were planted in 3.75-liter pots arranged in a randomized complete-block design with four replications and grown under the same regimes as for Expt. 1. Each replication contained 20 plants, one of each of the selected $\mathrm{F}_{3} \mathrm{~s}$. No guard plants were used.

The procedure for determining anthesis and fruit maturation dates was the same for this experiment as that described for Expt. 1. Five flowers per plant were tagged at anthesis from 31 Oct. -4 Dec. 1989, and breaker-stage fruit were harvested 15 Dec. 1989-26 Jan. 1990.

Realized heritability $\left(\mathrm{h}^{2}\right)$ of SFM was calculated as the difference between the high and low parent $\mathrm{F}_{3}$ means divided by the high and low parent $\mathrm{F}_{2}$ means. Narrow-sense heritability of SFM for the $\mathrm{F}_{3}-\mathrm{F}_{2}$ regression was calculated as the slope of the regression line multiplied by $2 / 3$.

\section{Results and Discussion}

Experiment 1. Pair-wise LSD tests of the seven generations revealed highly significant differences $(P=0.01)$ among all generations for FMP (Table 1). These small but significant differences resulted from very small LSD values (0.0317-0.0819).

A model was constructed to test the significance of the main effects and interactions. All effects proved to be highly significant (Table 2). The replication effect in the model indicated the presence of environmental influences for the expression of 
Table 1. Fruit maturation period (days from anthesis to the breaker stage of fruit ripening) in the tomato family NC $21 \mathrm{C}-1 \times$ Cornell 871213-1 (Expt. 1.).

\begin{tabular}{|c|c|c|c|c|}
\hline \multirow[b]{2}{*}{ Generations } & \multirow[b]{2}{*}{$\begin{array}{c}\text { Samples } \\
\text { (no.) }\end{array}$} & \multicolumn{3}{|c|}{ Maturation period } \\
\hline & & $\begin{array}{r}\text { Mean } \\
\text { (days) }\end{array}$ & $\begin{array}{c}\text { Sample range } \\
\text { (days) }\end{array}$ & $\mathbf{S}^{2}$ \\
\hline $\begin{array}{l}P_{2}(\text { Cornell 871213-1) } \\
F_{1 b}\left(P_{1} \times P_{2}\right)\end{array}$ & $\begin{array}{l}120 \\
120\end{array}$ & $\begin{array}{l}32.0^{z} \\
32.2\end{array}$ & $\begin{array}{l}25-38 \\
29-36\end{array}$ & $\begin{array}{l}1.0108 \\
1.0517^{y}\end{array}$ \\
\hline 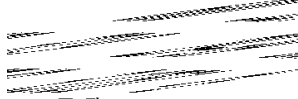 & - & 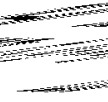 & 10 & \\
\hline
\end{tabular}

${ }^{7}$ All means significantly different $(P=0.01)$ using a pairwise LSD comparison. A pairwise test was used due to the unequal number of samples from each generation.

The data from both $F_{1 a}$ and $F_{1 b}$ were pooled to give one estimate of variance to be used in calculating heritabilities.

Table 2. Analysis of variance for the main effects and interactions in the model used in testing for differences in the tomato family NC 21C-1 × Cornell 871213-1 (Expt. 1).

\begin{tabular}{lrrrr}
\hline \hline Source $^{z}$ & df & Mean squares & F value & $P>\mathrm{F}$ \\
\hline Model & 575 & 34.1818 & 40.62 & 0.0000 \\
Reps & 11 & 169.4574 & 201.38 & 0.0000 \\
Gen & 6 & 1426.5219 & 1695.23 & 0.0000 \\
Samp/Gen & 41 & 11.3202 & 13.45 & 0.0000 \\
Rep*Gen & 66 & 7.7981 & 9.27 & 0.0001 \\
Rep*Samp/ & & & & \\
$\quad$ Gen & 451 & 14.7406 & 17.52 & 0.0000 \\
Error & 2304 & 0.8415 & & \\
\hline
\end{tabular}

${ }^{\mathrm{x}}$ Reps $=$ replications; Gen $=$ generations; Samp $=$ samples.

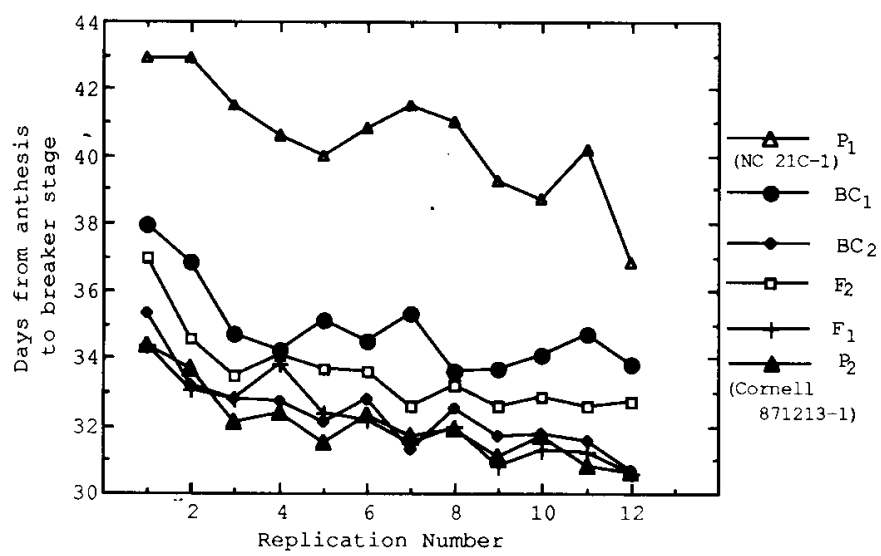

Fig. 1. Mean number of days from anthesis to the breaker stage of fruit maturation for each generation within a replication in the tomato family NC 21C-1 × Cornell 871213-1 (Expt. 1).

SFM. The early parent, Cornell 871213-1, matured in 34.4 days, on average, at the cool end of the greenhouse (Replication 1) as opposed to 30.6 days at the warm end (Replication 12), a difference of almost 4 days. Similar replication trends for days from anthesis to the breaker stage of fruit maturation occurred for each of the generations involved in the study (Fig. 1). More importantly, this figure reflects the relationships among the different genotypes. These data and the data from the model indicate that environment played a significant role in the variation exhibited in the expression of SFM.

Experiments 1 and 2. The segregation of single recessive genes in NC 21C-1 $(u$ and $j-2)$ and NC $84173(u)$ confirmed the purity of the $\mathrm{F}_{2}$ and backcross populations. The inability to detect discreet classes for the segregation of FMP and the failure to recover extremely late-maturing segregates in the large $F_{2}$ and backcross populations indicates that the genetic control of the SFM trait is quantitative.

The difference in number of days from anthesis to the breaker stage of fruit maturation in the greenhouse (Expt. 1) was greatest for the two parental lines (8.8 days) (Table 1$)$. The means of the $\mathrm{F}_{1} \mathrm{~s}$ and the backcross of NC 21C-1 to Cornell 871213-1 $\left(\mathrm{BC}_{2}\right)$ were very close to the mean for Cornell 871213-1 and lower than the midparent value (36.4 days) (Table 1$)$. The means of the $\mathrm{F}_{2} \mathrm{~S}$ and the backcross to $\mathrm{NC} 21 \mathrm{C}-1 \quad\left(\mathrm{BC}_{1}\right)$ also were strongly skewed toward the mean for Cornell 871213-1 and below the midpoint of the two parents (Table 1; Fig. 1).

In the field study, the greatest difference in number of days from anthesis to the breaker stage of fruit maturation was between the two parents (17.2 days). The means of all generations were significantly different from each other $(P=0.05)$ (Table 3 ). The $F_{1}$ and $F_{2}$ means were close to the Cornell 871213-1 mean and were lower than the midparent value (39.8 days). Although the mean FMP of individual $F_{2}$ plants varied from 30.2 days to 41.5 days, most of the values fell below the midparent value. The results from both of these studies indicate that SFM exhibited a high level of dominance in the crosses involved.

Results of our studies were similar to those reported by Powers and Lyon (1941), Lyon (1941), and Burdick (1954), although they defined earliness differently. In their studies, the value of the $F_{1} s$ were below the midparent value and close to the value of the early parent. They concluded, as we have, that dominance played a major role in the expression of earliness.

Tests (Hallauer and Miranda, 1981) for the presence of midparent heterosis in the greenhouse study of Expt. 1 and in the field study were significant $(P=0.01)$. Midparent heterosis was estimated as $10.7 \%$ and $16.9 \%$ for the greenhouse and field studies, respectively. The indication that heterosis influences the expression of SFM lends support to the conclusion that dominance is involved in the expression of SFM. Dominance, as stated by Fehr (1987), is believed to be one of the causes, or perhaps the cause, of heterosis.

No epistasis was indicated in the greenhouse study of Expt. 1. However, additive $\times$ additive interactions between the two homozygous parents may have existed (Banerjee and Kalloo, 1989; Fogel and Currence, 1950).

Broad- and narrow-sense heritabilities based on single-plant selection were estimated for SFM as $72 \%$ and $40 \%$, respectively, in the greenhouse study of Expt. 1. In the field study, broad-sense heritability of SFM in the $\mathrm{F}_{2}$ population from the cross Cornell 871213-1 × NC 84173 was estimated to be $64 \%$ on a single-plant basis. Using $\mathrm{F}_{3}-\mathrm{F}_{2}$ regression, the narrow-

Table 3. Fruit maturation period (days from anthesis to the breaker stage of fruit ripening) of the four generations in the tomato family Cornell 871213-1 × NC 84173 (Expt. 2/Part 1).

\begin{tabular}{lcccc}
\hline \hline Generations & $\begin{array}{c}\text { Samples } \\
\text { (no.) }\end{array}$ & $\begin{array}{c}\text { Mean } \\
\text { (days) }\end{array}$ & $\begin{array}{c}\text { Sample range } \\
\text { (days) }\end{array}$ & $\mathrm{S}^{2}$ \\
\hline $\mathrm{P}_{1}$ (Cornell 871213-1) & 48 & $31.2 \mathrm{a}^{\mathbf{2}}$ & $29-33$ & 0.8381 \\
$\mathrm{~F}_{1}$ & 48 & $33.1 \mathrm{~b}$ & $32-35$ & 0.4931 \\
$\mathrm{~F}_{2}$ (NC 84173) & 728 & $34.7 \mathrm{c}$ & $30-42$ & 4.3534 \\
$\mathrm{P}_{2}$ (NC) & 48 & $48.4 \mathrm{~d}$ & $46-51$ & 3.7911 \\
\hline
\end{tabular}

${ }^{x}$ Means significantly different $(P=0.05)$ according to LSD. 
sense heritability of SFM in the greenhouse study of Expt. 2 was estimated to be $39 \%$. Peirce and Currence (1959) calculated a similar heritability of $38.7 \%$ for days from sowing to first ripe fruit.

Broad-sense heritability is composed of additive gene effects plus nonadditive gene effects. Narrow-sense heritability is composed of additive gene effects only. The large difference between the broad- and narrow-sense heritabilities suggests a significant nonadditive component is involved in the expression of SFM.

In the field study, parental means differed from each other and from the $F_{1}$ and $F_{2}$ means for fruit weight, days from sowing to anthesis, and locule number (Table 4). $\mathrm{F}_{1}$ and $\mathrm{F}_{2}$ means did not differ for any of these three traits.

Mean fruit weights of the $F_{1} \mathrm{~s}$ and $\mathrm{F}_{2} \mathrm{~s}$, were strongly skewed towards the mean of the small-fruited parent, Cornell 8712131 (Table 4). Mean fruit weights for individual $\mathrm{F}_{2}$ plants varied from $23 \mathrm{~g}$ to $147 \mathrm{~g}$ and were far below the midparent value (211 g). Banerjee and Kalloo (1989) showed that small fruit size was partially dominant to large fruit size, and the means of the $F_{1}$ and $F_{2}$ were close to the mean of the small-fruited parent in a cross of large- $\times$ small-fruited parents. These results also concur with earlier reports (Butler, 1966; Fogel and Currence, 1950; MacArthur, 1941; MacArthur and Butler, 1938).

Mean locule numbers of the $\mathrm{F}_{1} \mathrm{~s}$ and $\mathrm{F}_{2} \mathrm{~s}$ were also skewed toward the mean of the small-fruited parent (Table 4). Although the mean locule number of individual $\mathrm{F}_{2}$ plants varied from 2.0 to 8.0 , most of the values fell below the midparent value $(4.3$ locules).

The mean number of days from sowing to anthesis of the individual $\mathrm{F}_{2}$ plants varied from 45.0 to 62.0 days, with most of the values for the $\mathrm{F}_{2}$ and the overall population means of the $\mathrm{F}_{2}$ and $\mathrm{F}_{2}$ below the midparent value (57 days) (Table 4). Tayel et al. (1959) reported similar findings in that the $F_{1}$ mean was skewed towards the mean of the early flowering parent.

Significant correlations occurred between FMP and fruit weight in the $\mathrm{F}_{2}$ generation $(0.61, P<0.0001)$ and in the $\mathrm{F}_{3}$ generation (0.48, $P<0.0329)$. These results are similar to earlier ones (Banerjee and Kalloo, 1989; MacArthur and Butler, 1938) showing positive correlations between fruit weight and the number of days from sowing to fruit ripening.

A significant correlation occurred in the $\mathrm{F}_{2}$ generation between fruit weight and locule count $(0.69, P<0.0001)$. Small, nonsignificant correlations occurred in the $\mathrm{F}_{2}$ generation between locule count and days from sowing to anthesis and between locule count and days from sowing to fruit ripening. In contrast, Banerjee and Kalloo (1989) and MacArthur and Butler (1938) found significant positive correlations between locule count and the number of days from sowing to fruit ripening.

In the $\mathrm{F}_{2}$ and $\mathrm{F}_{3}$ generations, correlation values were small

Table 4. Comparisons of means for three tomato fruit traits measured in $\mathrm{P}_{1}, \mathrm{P}_{2}, \mathrm{~F}_{1}$, and $\mathrm{F}_{2}$ generations from the cross Cornell 871213-1 $\times$ NC 84173 (Expt. 2; Part 1).

\begin{tabular}{lccc}
\hline \hline $\begin{array}{l}\text { Generation } \\
\text { no. }\end{array}$ & $\begin{array}{c}\text { Fruit fresh } \\
\text { wt }(\mathrm{g})\end{array}$ & $\begin{array}{c}\text { Locule } \\
\text { no. }\end{array}$ & $\begin{array}{c}\text { Days from sowing } \\
\text { to anthesis }\end{array}$ \\
\hline $\mathrm{P}_{1}(871213-1)$ & $15.6 \mathrm{a}^{\mathrm{z}}$ & $2.0 \mathrm{a}$ & $51.6 \mathrm{a}$ \\
$\mathrm{F}_{1}$ & $57.8 \mathrm{~b}$ & $3.5 \mathrm{~b}$ & $56.2 \mathrm{~b}$ \\
$\mathrm{~F}_{2}$ & $59.7 \mathrm{~b}$ & $3.5 \mathrm{~b}$ & $56.3 \mathrm{~b}$ \\
$\mathrm{P}_{2}$ (NC 84173) & $406.2 \mathrm{c}$ & $6.5 \mathrm{c}$ & $62.4 \mathrm{c}$ \\
\hline
\end{tabular}

${ }^{\mathrm{z}}$ Means followed by the same letter not significantly different $(P=$ $0.05)$ according to an LSD test. and nonsignificant between days from sowing to anthesis and fruit weight and between days from sowing to anthesis and FMP. In earlier studies, Khalf-Allah and Pierce (1963, 1964) found relatively early flowering to be associated with relatively small fruit size.

The mean difference between the number of days from sowing to anthesis of selected $\mathrm{F}_{2} \mathrm{~s}$ (54.8 days) and their $\mathrm{F}_{3}$ progeny (55.2 days) was 0.4 days. A highly significant correlation $(0.78$, $P<0.0001)$ existed between the two generations for days from sowing to anthesis. The square of this correlation indicates the percentage of variation in the independent variable (days from sowing to anthesis of the $F_{3}$ ) that can be attributed to the dependent variable (days from sowing to anthesis of the selected $\mathrm{F}_{2} \mathrm{~s}$ ). In this case, $\approx 61 \%$ of the variation in the $\mathrm{F}_{3}$ progeny for this trait can be attributed to the selected $\mathrm{F}_{2} \mathrm{~s}$, indicating that selection in successive generations should be successful for this trait. These results are similar to those reported by Tayel et al. (1959).

$\mathrm{F}_{3}-\mathrm{F}_{2}$ regression was used to estimate a narrow-sense heritability of $30.6 \%$ for the number of days from sowing to anthesis. A realized heritability of $29.5 \%$ was also calculated for this period. These estimates are lower than that reported by Tayel et al. (1959) of $54.4 \%$ for the number of days from sowing to anthesis.

The mean difference between the fruit weight of the selected $\mathrm{F}_{2} \mathrm{~s}(64.8 \mathrm{~g})$ and their $\mathrm{F}_{3}$ progeny $(37.9 \mathrm{~g})$ was $26.9 \mathrm{~g}$. A highly significant correlation $(0.78, P<0.0001)$ existed between the two generations for fruit weight. Peirce and Currence (1959) found a similar correlation $(0.84)$ between selected $\mathrm{F}_{2} \mathrm{~s}$ and their progeny for fruit weight and suggested that single-plant selection for fruit weight would be successful in segregating generations.

The mean FMP for the selected $\mathrm{F}_{2} \mathrm{~s}$ (35.5 days) and their $\mathrm{F}_{3}$ progeny ( 54.5 days) differed by 18.9 days. The large differences between the two generations for both FMP and fruit weight were attributed to their growth in two distinct environments (summer field and winter greenhouse). A significant correlation $(0.53, P$ $<0.0161$ ) was noted between the two generations for FMP. This indicates that $\approx 28 \%$ of the variation in the $\mathrm{F}_{3}$ progeny for SFM can be attributed to variation among the selected $\mathrm{F}_{2} \mathrm{~s}$. Thus, it would be difficult to realize genetic gain for this trait via individual plant selection.

The moderate positive correlations shown in these studies between fruit weight and FMP and the dominance shown here and in previous studies for small-fruit size indicate a need for large $\mathrm{F}_{2}$ populations to provide segregates combining increased fruit size and SFM. Because of the high level of dominance, moderate narrow-sense heritability, and environmental influence associated with the SFM character, progeny testing will be necessary to advance and fix this character through segregating generations. The lack of strong correlation for FMP between $\mathrm{F}_{2}$ and $\mathrm{F}_{3}$ generations in studies reported here support this breeding approach. The positive correlations between generations for fruit weight shown here and in previous studies and the high narrow-sense heritability shown in previous studies for fruit weight indicate that selection and advancement of improved fruit size should be effective. Also, the lack of correlation between fruit weight and the number of days from sowing to anthesis and between the number of days from sowing to anthesis and FMP should allow for effective selection of early flowering lines with large fruit size and of early flowering lines with SFM. 


\section{Literature Cited}

Banerjee, M.K. and Kalloo. 1989. The inheritance of earliness and fruit weight in crosses between cultivated tomatoes and two wild species of Lycopersicon. Plant Breeding 102:148-152.

Burdick, A.B. 1954. Genetics of heterosis for ealriness in the tomato. Genetics 39:488-505.

Butler, L. 1966. The inheritance of fruit size in $\mathrm{F}_{2}$ selections of the tomato. Genet. Agr. 20:266-274.

Corbeil, R. 1964. An analysis of maturation in tomatoes in terms of components of earliness. Tomato Genet. Coop. Rpt. 14:9-11.

Corbeil, R. and L. Butler. 1965. A genetic analysis of time to maturity in a cross between species of the genus Lycopersicon. Can. J. Genet. Cytol. 7:341-348.

Currence, T.M. 1938. The relation of the first chromosome pair to the date of fruit ripening in the tomato. Genetics 23:1-11.

Daubeny, H.A. 1961. Earliness in tomato varieties with special reference to the ability to set fruit at low temperatures. Proc. Amer. Soc. Hort. Sci. 78:445-449.

Fehr, W.R. 1987. Principles of cultivar development. Volume 1: Theory and Technique. Macmillan, New York. p. 115-119.

Fogel, H.W. and T.M. Currence. 1950. Inheritance of fruit weight and earliness in a tomato cross. Genetics 35:363-380.

Hallauer, A.R. and J.B. Miranda. 1981. Quantitative genetics in maize breeding. Iowa State Univ. Press, Ames.

Honma, S., S.H. Wittwer, and S.C. Phatak. 1963. Flowering and earliness in the tomato. J. Hered. 54:212-218.

Kerr, E.A. 1955. Some factors affecting earliness in the tomato. Can. J. Agr. Sci. 35:302-309.

Khalf-Allah, A.M. and L.C. Peirce. 1963. A comparison of selection methods for improving earliness, fruit size and yield in the tomato. Proc. Amer. Soc. Hort. Sci. 82:414-419.
Khalf-Allah, A.M. and L.C. Peirce. 1964. The effect of sib-mating on variation and selection of quantitative characters in the tomato. Proc. Amer. Soc. Hort. Sci. 85:471-477.

Konsler, T.R. and R.G. Gardner. 1990. Commercial production of staked tomatoes in North Carolina. Agr. Ext. Serv. N.C. State Univ. Pub. AG-405.

Lopez, A.P. 1960. Relation of earliness of some plant characteristics in the tomato. J. Agr. Univ. of Puerto Rico. 44:236-250.

Lyon, C.B. 1941. Inheritance of stages of earliness in an interspecific cross between Lycopersicon esculentum and L. pimpinellifolium. J. Agr. Res. 63:175-183.

MacArthur, J.W. 1941. Size inheritance in tomato fruits. J. Hered. 32:291-295.

Macarthur, J.W. and L. Butler. 1938. Size inheritance and geometric growth processes in the tomato fruit. Genetics 23:253-268.

Peirce, L.C. and T.M. Currence. 1959. The efficiency of selecting for earliness, yield, and fruit size in a tomato cross. Proc. Amer. Soc. Hort. Sci. 73:294-304.

Powers, L. 1939. Studies on the nature of the interactions of genes differentiating quantitative characters in a cross between Lycopersicon esculentum and Lycopersicon pimpinellifolium J. Genet. 39:139170.

Powers, L. and C.B. Lyon. 1941. Inheritance studies on duration of developmental stages in crosses within the genus Lycopersicon. J. Agr. Res. 63:129-148.

Tayel, M.A., S.A. Kamel, and M.E. Gafar. 1959. Inheritance of earliness in a cross between two varieties of tomato. Ann. Agr. Sci. 4:111-120.

Walkof, C. 1955. The double-backcross, a possible method of developing early, large-fruited strains of tomatoes useful for further crossing. Tomato Genet. Coop. Rpt. 5:31-32. 